\title{
ON MULTILINEAR COMMUTATORS OF MARCINKIEWICZ INTEGRALS IN VARIABLE EXPONENT LEBESGUE AND HERZ TYPE SPACES
}

\author{
LiWEI WANG AND Lisheng SHU
}

Abstract. Based on some pointwise estimates, we establish the boundedness of multilinear commutators of Marcinkiewicz integrals in variable exponent Lebesgue spaces, which in turn are used to obtain some boundedness results for such operators in variable exponent Herz and HerzMorrey spaces. Further, we consider the boundedness in variable exponent Herz-type Hardy spaces applying the atomic decomposition and generalization of the BMO norms.

Mathematics subject classification (2010): 42B20, 42B35, 46E30.

Keywords and phrases: Marcinkiewicz integrals, multilinear commutators, variable exponent, Herztype spaces.

\section{REFERENCES}

[1] A. Almeida And D. Drinem, Maximal, potential and singular type operators on Herz spaces with variable exponents, J. Math. Anal. Appl. 394 (2012), 781-795.

[2] A. Benedek, A. Calderón and R. Panzone, Convolution operators on Banach space valued functions, Proc. Nat. Acad. Sci. USA, 48 (1962), 356-365.

[3] Y. Chen, S. LEVINE AND R. RAO, Variable exponent, linear growth functionals in image restoration, SIAM J. Appl. Math. 66 (2006), 1383-1406.

[4] R. CoIfMAn, R. Rochberg AND G. Weiss, Factorization theorems for Hardy spaces in several variables, Ann. Math. 103 (1976), 611-635.

[5] D. CruZ-Uribe And A. FiorenZA, Variable Lebesgue Spaces: Foundations and Harmonic Analysis, Applied and Numerical Harmonic Analysis, Birkhäuser, Basel, 2013.

[6] D. Cruz-Uribe, A. Fiorenza and C. Neugebauer, The maximal function on variable $L^{p}$ spaces, Ann. Acad. Sci. Fenn. Math. 28 (2003), 223-238.

[7] L. Diening, Maximal function on generalized Lebesgue spaces $L^{p(\cdot)}$, Math. Inequal. Appl. 7 (2004), 245-253.

[8] L. Diening, P. Harjulehto, P. HästÖ And M. RU̇ŽIČKA, Lebesgue and sobolev spaces with variable exponents, volume 2017 of Lecture Notes in Mathematics, Springer, Heidelberg, 2011.

[9] Y. Ding, D. FAN AND Y. PAN, $L^{p}$-boundedness of Marcinkiewicz integrals with Hardy space function kernel, Acta. Math. Sin. (Engl. Ser.), 16 (2000), 593-600.

[10] Y. Ding, S. LU AND Q. XUE, Marcinkiewicz integral on Hardy spaces, Integr. equ. oper. theory 42 (2002), 174-182.

[11] Y. Ding, S. LU AND P. ZHANG, Weighted weak type estimates for commutators of the Marcinkiewicz integrals, Sci. China Ser. A. 47 (2004), 83-95.

[12] D. Drihem And F. SeghiRI, Notes on the Herz-type Hardy spaces of variable smoothness and integrability, Math. Inequal. Appl. 19 (2016), 145-165.

[13] J. Garcia-Cuerva And J. L. Rubio DE Francia, Weighted norm inequalities and related topics, North-Holland, Amsterdam, 1985.

[14] L. Grafakos And R. H. Torres, Multilinear Calderón-Zygmund theory, Adv. Math. 165 (2002), $124-164$.

[15] P. Harjulehto, P. HÄstö, Ú. V. Lê AND M. Nuortio, Overview of differential equations with non-standard growth, Nonlinear Anal. 72 (2010), 4551-4574. 
[16] M. IZUKI, Herz and amalgam spaces with variable exponent, the Haar wavelets and greediness of the wavelet system, East J. Approx. 15 (2009), 87-109.

[17] M. IZUKI, Boundedness of commutators on Herz spaces with variable exponent, Rend. Circ. Mat. Palermo. 59 (2010), 199-213.

[18] M. IZUKI, Commutators of fractional integrals on Lebesgue and Herz spaces with variable exponent, Rend. Circ. Mat. Palermo. 59 (2010), 461-472.

[19] M. IZUKI, Fractional integrals on Herz-Morrey spaces with variable exponent, Hiroshima Math. J. 40 (2010), 343-355.

[20] A. KARLOVICH AND A. LERNER, Commutators of singular integrals on generalized $L^{p}$ spaces with variable exponent, Publ. Nat. 49 (2005), 111-125.

[21] O. KovÁČIK AND J. RÁKosníK, On spaces $L^{p(x)}$ and $W^{k, p(x)}$, Czechoslovak Math. J. 41 (1991), 592-618.

[22] A. LERNER, Weighted norm inequalities for the local sharp maximal function, J. Fourier Anal. Appl. 10 (2004), 465-474.

[23] F. LiU, Integral operators of Marcinkiewicz type on Triebel-Lizorkin spaces, Math. Nachr. 290 (2017), 75-96.

[24] F. LIU, On the Triebel-Lizorkin space boundedness of Marcinkiewicz integrals along compound surfaces, Math. Inequal. Appl. 20 (2017), 515-535.

[25] F. LiU, A note on Marcinkiewicz integrals associated to surfaces of revolution, J. Aust. Math. Soc. 104 (2018), 380-402.

[26] F. LiU, Z. FU, Y. ZHeng AND Q. YUAN, A rough Marcinkiewicz integral along smooth curves, J. Nonl. Sci. Appl., 9 (2016), 4450-4464.

[27] F. LiU AND H. WU, $L^{p}$ bounds for Marcinkiewicz integrals associated to homogeneous mappings, Monatsh. Math. 181 (2016), 875-906.

[28] F. LiU, H. WU AND D. Zhang, $L^{p}$ bounds for parametric Marcinkiewicz integrals with mixed homogeneity, Math. Inequal. Appl. 18 (2015), 453-469.

[29] F. LiU And D. Zhang, Parametric Marcinkiewicz integrals associated to polynomials compound curves and extrapolation, Bull. Korean Math. Soc. 52 (2015), 771-788.

[30] S. LU AND L. XU, Boundedness of rough singular intergral operators on the homogeneous MorreyHerz spaces, Hokkaido Math. J. 34 (2005), 299-314.

[31] S. LU AND D. YANG, The continuity of commutators on Herz-type spaces, Michigan Math. J. 44 (1997), 255-281.

[32] S. Lu, D. YANG AND G. Hu, Herz type spaces and their applications, Science Press, Beijing, 2008.

[33] Y. LU AND Y. ZHU, Boundedness of multilinear Calderón-Zygmund singular operators on MorreyHerz spaces with variable exponents, Acta Math. Sin. (Engl. Ser.), 30 (2014), 1180-1194.

[34] Y. Meyer And R. R. Coifman, Wavelets: Calderón-Zygmund and multilinear Operators, Cambridge Stud. Adv. Math., Cambridge University Press, 2000.

[35] A. NeKVINDA, Hardy-littlewood maximal operator in $L^{p(x)}\left(\mathbb{R}^{n}\right)$, Math. Ineq. Appl. 7 (2004), 255 265.

[36] C. PÉREZ, Endpoint estimates for commutators of singular integrals, J. Funct. Anal. 128 (1995), 163 185.

[37] C. PÉREZ AND R. TRUjILlo-GoneÁLEZ, Sharp weighted estimates for multilinear commutators, J. London Math. Soc. 65 (2002), 672-692.

[38] M. RagusA, Homogeneous Herz spaces and regularity results, Nonlinear Anal. 71 (2009), 1909_ 1914.

[39] M. RÜŽIČKA, Electrorheological fluids: modeling and mathematical theory, Springer-Verlag, Berlin, 2000.

[40] S. Samko, Variable exponent Herz spaces, Mediterr. J. Math. 10 (2013), 2007-2025.

[41] E. M. Stein, On the functions of Littlewood-Paley, Lusin and Marcinkiewicz, Trans. Amer. Math. Soc. 88 (1958), 430-466.

[42] E. M. SteIn, Harmonic Analysis: Real-Variable Methods, Orthogonality, and Oscillatory Integrals, Princeton University Press, Princeton, 1993.

[43] A. Torchinsky AND S. WANG, A note on the Marcinkiewicz integral, Colloq. Math. 60/61 (1990), 235-243.

[44] H. WANG, Z. FU AND Z. LIU, Higher order commutators of Marcinkiewicz integrals on variable Lebesgue spaces, Acta Math. Sci. Ser. A Chin. Ed. 32 (2012), 1092-1101. 
[45] H. WANG AND Z. LiU, The Herz-type Hardy spaces with variable exponent and thier applications, Taiwanese. J. Math. 16 (2012), 1363-1389.

[46] L. WANG AND L. SHU, Higher order commutators of Marcinkiewicz integral operator on HerzMorrey spaces with variable exponent, J. Math. Res. Appl. 34 (2014), 175-186.

[47] J. XU, The boundedness of multilinear commutators of singular integrals on Lebesgue spaces with variable exponent, Czechoslovak Math. J. 57 (2007), 13-27.

[48] X. YAn, D. YAnG, W. YuAn And C. Zhuo, Variable weak Hardy spaces and their applications, J. Funct. Anal. 271 (2016), 2822-2887.

[49] D. YAng, C. Zhuo AND W. YuAn, Triebel-Lizorkin type spaces with variable exponents, Banach J. Math. Anal. 9 (2015), 146-202.

[50] D. YANG, C. ZHUO AND W. YUAN, Besov-type spaces with variable smoothness and integrability, J. Funct. Anal. 269 (2015), 1840-1898.

[51] P. ZHANG, Weighted estimates for multilinear commutators of Marcinkiewicz integral, Acta Math. Sin. (Engl. Ser.), 24 (2008), 1387-1400.

[52] P. ZHANG AND J. WU, Commutators for the maximal function on Lebesgue spaces with variable exponent, Math. Inequal. Appl. 17 (2014), 1375-1386. 